\title{
El pediatra que impacta en el desarrollo infantil
}

\section{The pediatrician who impacts on child development}

Lidia María Prado López*

El tipo de alimentos que ingerimos tienen un impacto importante en nuestra salud. Existen estudios epidemiológicos a gran escala sobre la dieta y enfermedades crónicas que han facilitado avances en nuestro entendimiento sobre la contribución de la dieta en la patogénesis de éstas enfermedades. Es así que una alimentación inadecuada en la infancia, puede aumentar el riesgo de desarrollar numerosos trastornos crónicos como cáncer, hipertensión arterial, enfermedad cardiovascular, diabetes mellitus tipo 2, obesidad y osteoporosis.

El retraso en el crecimiento físico en menores de 2 años de edad ocasiona reducción de la función y actividad inmune, incrementa las tasas y severidad de las infecciones entéricas y otras enfermedades infecciosas, e incrementa el riesgo de morir prematuramente, ya que un tercio o la mitad de las muertes en menores de 5 años son atribuibles a desnutrición proteico calórica. Además, produce retraso en el desarrollo psicomotor y disminución de la función cognitiva y del desempeño escolar. La contraparte, una nutrición adecuada, es esencial en la infancia temprana para asegurar un crecimiento saludable, la adecuada formación y función de los órganos en crecimiento, un sistema inmune competente y un desarrollo neurológico y cognitivo apropiado.

Esto convierte a los 2 primeros años de vida en un período crítico, donde se modifica la salud del futuro adulto. Para ilustrar este hecho está el ejemplo de la exposición a la proteína de leche de vaca antes del año, la proteína de leche de vaca provoca la alergia a alimentos más común en niños pequeños y marca el inicio de la conocida marcha atópica, con la

*Director general APH, Pediatra HNMCR, Profesor Escuela Universitaria de las Ciencias de la Salud, UNAH-VS

Dirigir correspondencia a: lidia.prado@unah.edu.hn

Recibido: 10 de marzo 2017 Aprobado: 15 de marzo 2017 progresión de dermatitis atópica en la infancia a rinitis alérgica y asma en la niñez y la adultez temprana. Por otro lado, la leche humana tiene propiedades inmunológicas demostradas en ratones de laboratorio a quienes se les expuso a alergenos y a leche materna. El resultado fue que se estimuló la inducción de células T reguladoras y la tolerancia a alergenos específicos. ${ }^{(1)}$ Además, se ha definido el intervalo entre los 4-6 meses de vida, como un "período de ventana inmunológica decisivo", durante el cual el desarrollo del sistema inmune favorece la tolerancia de alimentos potencialmente alergenicos. También hay pruebas de que si existe una colonización intestinal favorable junto con la lactancia materna exclusiva en el momento en que se inicia la alimentación complementaria y se mantiene la lactancia materna durante los 6 meses posteriores se promueve la tolerancia a alimentos y tiene efectos protectores durante el período de la ablactación. ${ }^{(2)}$ Podrá usted enriquecer sus conocimientos sobre esto en las 3 revisiones bibliográficas que se presentan en este número: fundamentos sobre alimentación del lactante, Importancia de la nutrición: Primeros mil días de vida y Parte 1: Alergia a la Proteína de la Leche de Vaca.

Surge por lo tanto la interrogante, ¿cómo podemos los pediatras impactar en el desarrollo infantil? Al leer esta interrogante usted pensará que ya lo sabe, o que usted considera que son recomendaciones que ya ejerce en su consultorio, pero la realidad de lo que sucede con los niños está lejos de lo que pensamos. Se presenta en este número de la revista un artículo donde se describe las prácticas de alimentación inadecuadas que las madres proporcionan a los lactantes que asisten al HNMCR. Claro está que estas madres no asisten a su consultorio, y que la forma en que se puede incidir con mayor éxito es enseñar a los niños en las escuelas sobre lactancia materna y alimentación ade- 
cuada, pero como gremio organizado de Médicos Especialistas en Pediatría se puede intervenir desarrollando e impulsando las normas de alimentación, se puede trabajar en conjunto con el Ministerio de Educación para su difusión y práctica, y con el Congreso Nacional se pueden desarrollar las políticas públicas de alimentación, y que se regule el tipo de alimentos que se proporcionan en las cafeterías de las escuelas.

Es fácil colocar en las órdenes médicas Lactancia materna o Fórmula maternizada 1 onza cada 3 horas, pero debemos recordar que el papel principal del pediatra es promover la lactancia materna exclusiva. En la práctica privada, la enfermera prefiere dar la FM porque refieren que la madre está incómoda y se pierde la oportunidad de darle tan grande beneficio al bebe y su familia. Tan importante es el apego precoz que se deben retrasar los procedimientos de rutina (toma de peso, medición, baño, análisis de sangre, vacunas y profilaxis ocular) hasta después de la primera alimentación. Se puede esperar hasta 6 horas del nacimiento para aplicar la vitamina $\mathrm{K}$ en espera de que el bebé se alimente. En este punto es esencial la colaboración con el obstetra para desarrollar programas óptimos de apoyo a la lactancia materna, al promover la consulta con el pediatra previa al parto. Además, de promover la suplementación de nutrientes apropiados a la madre durante el embarazo, prevenir enfermedades infecciosas con las vacunas que se aplican durante el embarazo como la vacuna de la influenza y la vacuna DPT acelular. Esta última en todo embarazo a partir de las 27 a las 36 semanas de gestación. Promover en la consulta preconcepcional, las vacunas que se aplican antes del embarazo como SRP, varicela y VPH.

En cuanto a los suplementos recomendados para el bebe se encuentran la vitamina D $400 \mathrm{UI}$ al día en todos los lactantes amamantados desde el momento en que se da el alta hospitalaria. Esto es por el riesgo aumentado de deficiencia/ insuficiencia de vitamina $D$ y de raquitismo en todos los bebés. Se debe recordar que el fluoruro suplementario no debe proporcionarse durante los primeros 6 meses, sino a partir de los 6 meses hasta los 3 años. Y se debe tomar en cuenta de que, si la madre lava los dientes con pasta dental de niños fluorada 2 veces al día, proporciona los requerimientos diarios de flúor como para prevenir caries y no necesita suplemento adicional. La dieta de la madre debe incluir una ingesta diaria promedio de 200 a 300 mg del suplemento Omega 3 (Ácido docosahexaenoico [DHA]) para garantizar una concentración suficiente de DHA preformado en la leche. Por lo que el consumo de 1 a 2 porciones de pescado (arenque, atún enlatado, salmón) por semana cubrirá esta necesidad.

Debemos mantener el apoyo a la formación y educación de los estudiantes de medicina, en pregrado y posgrado en todos los aspectos relacionado con la alimentación ya que de ellos depende el cuidado futuro de los niños.

El pediatra que impacta positivamente en el desarrollo infantil es el que se ocupa de la nutrición de los niños.

\section{BIBLIOGRAFÍA}

1. Verhasselt V, Milcent V, Cazareth J, Kanda A, Fleury S, Dombrowicz D, et al. Breast milk-mediated transfger of an antigen induces tolerance and protection from allergic asthma. Nat Med. 2008; 14 (2):170.
2. Prescott $S L$, Smith $P$, Tang $M$, Palmer DJ, Sinn J, Huntley SJ. The importance of early complementary feedings in the development of oral tolerance: concerns and controversies. Pediatr Allergy Immunol 2008 Aug; 19 (5): 375-80.

DOI: $10.1111 /$ j.1399-3038.2008.00718x. 